2020-01-31

The Configuration Structure of Service Supply Chain Management

Somabutr, Sutinee

http://hdl.handle.net/10026.1/16888

10.1145/3383845.3383892

Proceedings of the 2020 the 3rd International Conference on Computers in Management and Business

ACM

All content in PEARL is protected by copyright law. Author manuscripts are made available in accordance with publisher policies. Please cite only the published version using the details provided on the item record or document. In the absence of an open licence (e.g. Creative Commons), permissions for further reuse of content should be sought from the publisher or author. 


\title{
The Configuration Structure of Service Supply Chain Management
}

\author{
Sutinee Somabutr \\ Plymouth Business School \\ Faculty of Arts and Humanities \\ University of Plymouth \\ Plymouth, United Kingdom \\ tss.sutinee@gmail.com
}

\author{
Shunmugham Pandian \\ Plymouth Business School \\ Faculty of Arts and Humanities \\ University of Plymouth \\ Plymouth, United Kingdom \\ shunmugham.pandian@plymouth. \\ ac.uk
}

\author{
Saeyeon Roh \\ Plymouth Business School \\ Faculty of Arts and Humanities \\ University of Plymouth \\ Plymouth, United Kingdom \\ saeyeon.roh@plymouth.ac.uk
}

\begin{abstract}
In spite supply chain management is obtaining more attention from researchers, academics and practitioners still mainly conduct research on manufacturing or traditional supply chain management rather than service supply chain management perspective because of nature of industry's complexity. So, research on service supply chain is immature and there is still some deficiency to study on service supply chain management. The main purpose of this research is to identify the configuration structure of service supply chain management by applying the case study of the shooting range sport center in Northeastern, Thailand. Definitions and concept of service supply chain are suggested in the literature review section. Primary data is mainly collected through semi-structured interviews and secondary data is reviewed systematically from academic journals and database. By exploring the configuration structure of service supply chain, the conceptual framework is illustrated to identify the relationship which consider the nature of service supply chain in the particular case study. Finally, the conclusion section is discussed.
\end{abstract}

\section{Keywords}

service supply chain management; sport industry; service supply chain structure

\section{INTRODUCTION}

In the last decades, it is generally accepted that the service sector has played the significant role in many countries [1]. At present, the service sector is required to improve internal service operations, minimize cost and increase efficiency and effectiveness [1]. Regarding to the dynamic technology evolution, increasing customer satisfaction while responding rapid changeable customer's preference is challenging and competitive [2]. Supply chain management is the vital perspective that almost all industries have implemented so far via the manufacturing aspect. But the service supply chain management research is still getting less attention than manufacturing supply chain management because of complicated service characteristics; which are perishable, intangibility, simultaneity and heterogeneity, and difficult to measure the performance along the service chain [3]. While diverse business areas of research in service supply chain management such as airlines, restaurant, hospital [4], [5], [6], hotel [7], [8], education [9], logistics [6], [10], consulting [11] and so forth, there is a dearth of evidence has investigate how service providers in sport industry manage the service supply chain that may improve firm service. The inherent problem for service supply chain implementation for sport industry is almost all about the data inaccessibility. Therefore, this research has studied to fill the gap by empirically applying service supply chain management perspective to the case study of shooting sport. For this reason, the aim of this study is to identify the configuration structure of service supply chain management by applying the case study of the shooting range sport center in Northeastern, Thailand.

Moreover, this research contributes to the improvement of service supply chain management implementation through the case study. Scholars expect that this research can encourage and guide the rest of shooting range sport centers in Thailand to be drawn and highlighted the processes of service supply chain management. Consequently, service providers from the shooting range sport center in Northeastern, Thailand can improve and spot on the related process, meanwhile, customer would get more satisfaction and faster service.

The paper is further organized into four sections. The next section gives a comprehensive on current state of research which mainly states about the concept of service supply chain management; following a methodology section clarifying the research approach. Then the originality and discussion are explained about the proposed framework with the case study of the shooting range sport center in Northeastern, Thailand. The conclusion is provided in the final section.

\section{THE CONCEPT OF SERVICE SUPPLY CHAIN MANAGEMENT}

While there has been a great deal of research on supply chain management, very few studies about service supply chain management. In recent decades, the research on service supply chain has just been carried out about identifying definitions [2], [4], [12], structure of service supply chain [4], [12],[13], and empirical case study base on theoretical service supply chain concept [11], [12],[13]. Basically, service supply chain has been defined by several researchers. Table 1 demonstrates each definition.

Table 1: Service Supply Chain Management definitions

\begin{tabular}{|l|l|}
\hline \multicolumn{1}{|c|}{ Author } & \multicolumn{1}{|c|}{ Definition } \\
\hline $\begin{array}{l}\text { Baltacioglu } \\
\text { et al. [4] }\end{array}$ & $\begin{array}{l}\text { Service supply chain is the network of } \\
\text { suppliers, intermediary, service providers, } \\
\text { customers and other supporting parties that }\end{array}$ \\
\hline
\end{tabular}




\begin{tabular}{|l|l|}
\hline & $\begin{array}{l}\text { takes responsibility about the function of } \\
\text { transaction of resources, products } \\
\text { transformation and product delivery. }\end{array}$ \\
\hline Wu et al. [6] & $\begin{array}{l}\text { Service supply chain is an integration of a } \\
\text { chain of entities to provide service directly or } \\
\text { indirectly to customer. }\end{array}$ \\
\hline $\begin{array}{l}\text { Ellram et al. } \\
\text { [13] }\end{array}$ & $\begin{array}{l}\text { Supply chain management is the management } \\
\text { of information, processes, service performance, } \\
\text { capacity and financial from the supplier to the } \\
\text { customers. }\end{array}$ \\
\hline Li et al. [14] & $\begin{array}{l}\text { Service supply chain can be defined as the } \\
\text { service-network that arranges the service } \\
\text { entities for delivering services the customers by } \\
\text { applying technology. }\end{array}$ \\
\hline $\begin{array}{l}\text { He et al. } \\
\text { [15] }\end{array}$ & $\begin{array}{l}\text { Service supply chain can be identified as the } \\
\text { management model of supply and demand } \\
\text { chain which combines the service and } \\
\text { technology. }\end{array}$ \\
\hline
\end{tabular}

The study of Ellram et al [13] has become a key aspect of service supply chain in terms of raising awareness of the service importance and explaining the comparison among three frameworks such as H-P, SCOR and GSCF models. This study sought to shed light on a unifying framework for understanding the service supply chain management.

In 2007, Baltacioglu et al [4] investigated the IUE-SSC model based on the existing knowledge from Ellram et al model [13]. The IUE-SCC framework is a robust model for further research in terms of implementing the service supply chain management context in healthcare industry and providing the strategies in each process.

In this section, we present some fundamental ideas underlying the service supply chain processes from the existing literature reviews [1], [11], [13]. So basically, it is generally accepted wisdom that there are seven processes in service supply chain such as demand management, capacity and resources management, customer relationship management, supplier relationship management, order process management, service performance management and information technology management [2], [4],[13].

As from the theoretical studies of Ellram et al [13] and Baltacioglu et al [4] are extended by seven constructs as following:

\subsection{Demand Management}

Demand management is the basic activity of service supply chain management. It can be defined as estimating forecasts and managing customer demand by applying the real time information to the demand plan and shaping the service capacity [2], [13]. This activity is challenging for service firm in terms of determining and facing with demand uncertainty and highest and lowest points of sale.

\subsection{Capacity and Resources Management}

Capacity and resource management can be defined as the activity in balancing demand from customers and firm's service capacity at the optimum capacity [2], [10], [13]. Due to the customer demand is fluctuated and miscellaneous, almost all every firm has the problem about balancing the customer demand with the prepared service capacity. In terms of solving this problem, service firms are required to maintain and keep the level of optimum service capacity with the customer demand for example rescheduling the work shift or number of employees.

\subsection{Customer Relationship Management}

Customer relationship management has been defined as the ability in interacting with internal firms and customers, creating the customer demand and developing long-term customer relationship by using real-time information technology. In addition, improving communication with customers and understanding the prediction of customer demand can also lead to customer relationship management and customer royalty [2], [4].

\subsection{Supplier Relationship Management}

Supplier relationship management is the ability to manage and maintain a relationship between firms and its suppliers [16]. Supplier relationship management is the core process for every business which supports, plans, sources material, and coordinates with suppliers [4]. Additionally, supplier relationship management can help firms to have faster service at the minimize cost by having the strong collaborations.

\subsection{Order Process Management}

Order process management process has been described as the activity in getting orders from customers, examining the order status and interacting with customer [4]. This function is critical for service firms because the physical goods manufacturer can produce before customer places the order, but service is delivered after the order is received. At present, order process management has important impacts on customer's perception in many ways for example customers nowadays can place order from automatic kiosks to avoid the mistake from getting order by human, they can also track their order by application as the order status report and customer might interact with firm directly via real time conversation platform [4], [13].

\subsection{Service Performance Management}

Service performance management is the ability to manage, improve the performance of service process and fulfill the customer requirement [4]. It involves many aspects such as service delivery management, order process management and other activities [17]. Service performance might be measured simultaneously when during and after the service is being served [1]. This process is related directly with human resource skills and performance, so it can be included talent management within organization and rewarding system to boost up the employee's performance and meet customer expectation. Hence, service performance management can maintain the service quality and customer loyalty.

\subsection{Information and Technology Management}

Information and technology management is the ability in sorting customer demand, sharing information among the firm supply chain, establishing expectation, shaping the scope of job description, service and required skills for service firm, and following up the customer feedback regarding service [4], [6], [11], [13], [17]. In terms of having the decision-making, information technology management might help avoid uncertainty demand by updating the historical data from customer purchasing, after-sale service or feedback with the coming customer demand. Almost all issues in firm can be solved by getting adequate information and using the appropriate technology devices and 
networks [1]. In addition, information technology management implementation supports the internal and external collaboration, increases firm's operation efficiency and effectiveness and share useful information to the customer as the advertisement. Therefore, Information technology management is the key enabler in every function of firm to manage seamless operation system and provide information sharing system to the customers [1], [6], [11], [17].

From the literature of service supply chain management, research has been carried out in several areas such as airlines, restaurant, hospital [4], [5], [6], hotel [7], [8], education [9], logistics [6], [10], consulting [11] and so forth. There is limited research investigating the service systems of sport center. Regarding to the current research trend in service supply chain management, a conceptual framework by applying the case study of the shooting range sport center in Northeastern, Thailand is proposed. The proposed conceptual framework has been highlighted the nature of service system in sport center and the theoretical understanding based on the service supply chain management concept.

\section{METHODOLOGY}

Based on the literature review, this research on service supply chain aims to provide the structure of service supply chain case study of the shooting sport center in Northeastern, Thailand and to identify the uniqueness of its nature of service operations of the shooting range sport center. More specially, this research has been conducted primary data by field observation with authorized permission to the weapons warehouse and semi-structured interviews from the 10 staffs and 2 managers of the shooting range center in order to understand the service system. Additionally, some customers provided information about the order process management and other information. Suggestions and opinions from experts of supply chain management field also provided some direction to organize the configuration structure of service supply chain management.

\section{FINDING AND DISCUSSION}

The research results are mainly described from analyzing the data collection from the shooting range sport center in Northeastern, Thailand and are concluded into a framework.

\subsection{Case Study}

Shooting sport is the series of proficiency of accuracy, speed, and precision. Basically, every sport has its own equipment to use but shooting sports is quite unique in terms of a variety of weapons such as firearm, air pistol, riffles, handguns and shotguns, distance in 10, 25 and 50 meters, electronic and paper target and time limits for each section. Shooting sport is open for individual and team competitions by counting the accumulative scores from every target. As from the test of accuracy and precision, the main objective of this sport is to gain the most scores as possible by hitting the nearest center point of each target.

In Thailand, shooting sport is adventurous and exciting for all ages. There are two rounds for national games every year such as Thailand national games and Thailand national youth games for people between 15 to 25 years of age. Basically, Shooting is the sport which is required several things before entering to the shooting range such as prepared the registered weapons (i.e. pistol, riffle), appropriate bullets for each type of weapon, different sizes of target papers, and shooter license or membership card. The problem is service configuration structure in this case is still vague and complicated. The service supply chain structure in this research is described in Figure 1.

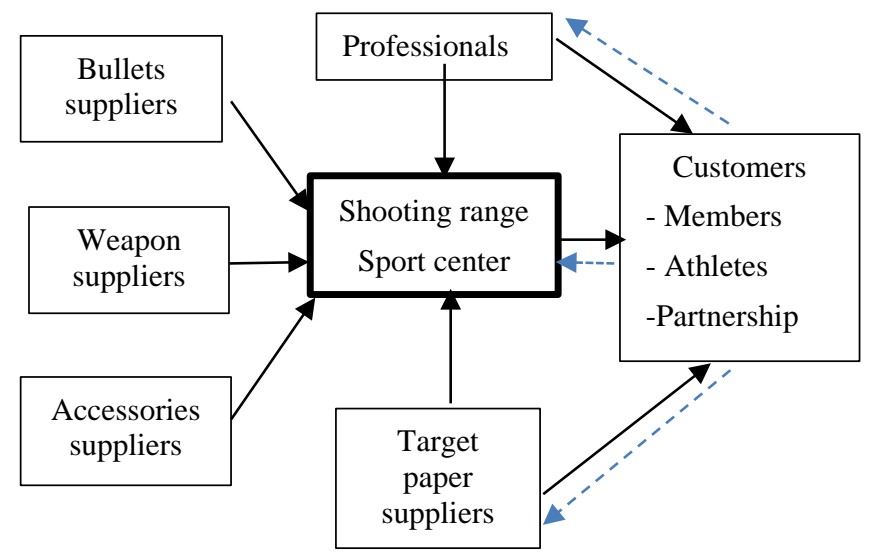

Figure 1: Service supply chain process in the shooting range Sport center, Thailand

The service supply chain study in this research is consisted of a shooting range center as the focal unit which provides the service and vacant ranges to customers; suppliers providing the bullets, paper targets, and other accessories (special clothes, shoes and eye glasses); coach or consultancy serving the professional service, the shooting techniques from basic to advance lessons and exercising programmed for athletes. The special feature of service supply chain is bidirectional relationship [17]. In this given framework, customers would have bidirectional contact with the focal unit or the shooting range center and other suppliers such as professionals and target paper company. The customers can be the supplier at the same time because service cannot be stored or produced in advance. The customer requires to consume simultaneously when they presented [17].

\subsection{Application of Service Supply Chain Management to the Case Studies}

From the literature of service supply chain management, it is necessary to study and understand the process of each stage of service supply chain management concept. In order to combine the case study of shooting range sport center with the service supply chain concept, the figure 2 shows the seven constructs of service supply chain management. The figure 2 has been divided into three sections; customer-facing processes, supplier processes and overlapping processes. Firstly, customer-facing processes are about the processes that firm needs to interact or communicate directly with customers. Customer-facing processes are consisted of Customer relationship management, order process management and service performance management [2]. Secondly, supplier processes are mainly about the core process of maintaining, developing the relationship with suppliers. These processes are also related about prioritizing the supplier's performance. Thirdly, overlapping processes are about the combination between customer-facing process and supplier processes which are required to apply along the all service process in firm. 


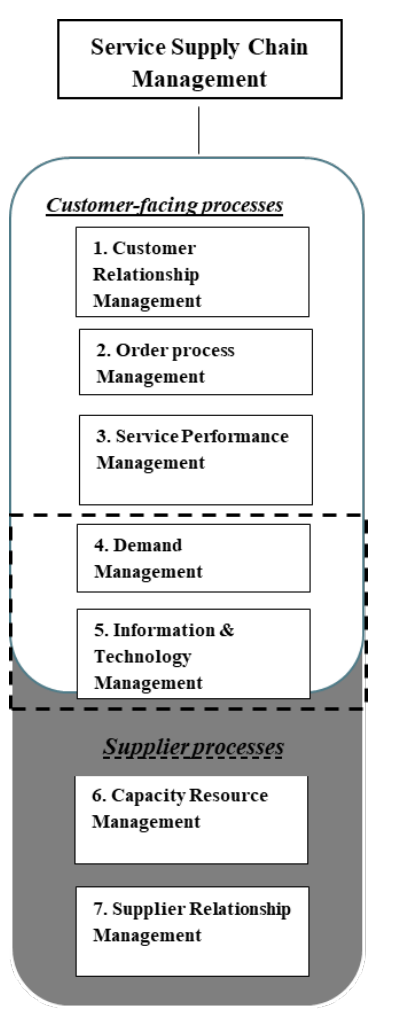

Figure 2: Service supply chain process

In terms of application the service supply chain management concept to the case study of the shooting range sport center in Thailand, each stage is described as following:

\subsubsection{Demand management}

Demand management process is mainly about forecasting, creating customer demand and keeping the real-time information within firm [3], [4], and [13].

In this case study, the focal unit or the shooting range sport center can adapt this prior function by estimating the number of general members or athletes. The staffs may create the customer demand by suggesting more promotion of accessories orders and inputting the real time customer information into the Point-of-Sale programme (POS system).

\subsubsection{Capacity and resource management}

Capacity and resource management process is about the process of balancing and managing the customers demand and firm service capacity [13]. In this process, the focal unit or the shooting range sport center requires to balance the customer demand by keeping the number of rental weapons for general customers and athletes, target papers or vacant electronic targets and different types of bullets with the nearest optimum point of stocks. In addition, this process is encouraged the staffs to manipulate the facilities, inventory and professional scheduling.

\subsubsection{Customer relationship management}

Customer relationship management has been suggested as the ability to understand, manage and assess the customer satisfaction [4]. Customer relationship management in this case study includes obtaining the information of customer demand or preferences e.g. schedules, special coach and so forth, communicating with athletes and other shooting clubs and tracking the customer programme or satisfaction. The effective customer relationship management function can be successful by integrating customer feedback with the given information from the demand management function.

\subsubsection{Supplier relationship management}

Supplier relationship management is also important to every sector [17]. Basically, this function includes selecting the suppliers, developing the strong relationship and sourcing the new supplier in order to handle with the risk situation or uncertain demand [5]. In this case, the focal unit or the shooting range sport center requires the strong collaboration with the critical suppliers such as weapons (pistols, rifles, and other types), target paper companies, electronic target companies, professional team from the reliable organizations and some accessories international importers. In terms of achieving successful supplier relationship management, the focal unit always needs to assess the supplier performance and every single product quality and team usually sources the new suppliers in order to have power of decision making.

\subsubsection{Order process management}

The order process management function in the case study of the shooting range sport center covers many sub-processes such as order preparation which is mainly about the vacant shooting ranges scheduling, order entry from customers, order filling to stocks, real-time order status report, order information management. Therefore, this function has a critical impact on customer's perception and satisfaction. In terms of customerfacing process, receiving the right types of weapons, bullets, and targets are important for playing this sport. Failure in this function may cause the problems on the effectiveness of firm operations for example some type of bullet has sensitive price, authorized needed and long leading time when ordering. So, every order from customer requires to consider correctly before handing to suppliers [5].

\subsubsection{Service performance management}

Service performance management is about the ability to serve and fulfill the customer demand [3]. The shooting range sport center may involve with many processes such as assessing the service delivering performance, order process management and skilledlabour management. This process is mainly about human resource management because of its nature of characteristics of service that service performance can be measured after customer consumes it. In addition, service performance generally relates to customer satisfaction.

\subsubsection{Information technology management}

The importance of improving supply chain management performance is based on the implementation of information technology management process [6]. In this case study, it should be noted that information technology management is required for all activities in service supply chain. The aims of information technology in the shooting range sport center are providing the right data or accurate demand before placing orders and applying the suitable software and programme at Point-of-Sale (POS) and stock rooms. Information Technology management is key activity which connects all processes for effective service supply chain management [1]. 
Consequently, the successful of service supply chain management has been suggested that all seven activities in service supply chain concepts should be linked together to develop the overall firm performance and increase overall customer's satisfaction.

\section{CONCLUSION}

As traditional supply chain management is becoming more significant, service supply chain management is also obtaining attention for theoretical and methods development. Service supply chain perspective deserves to study and implement specially in the service industry rather than applying the traditional supply chain perspective to the service industry because of measurement dimensions. Therefore, this research provides insight into the configuration structure of service supply chain management field. In addition, this paper extends the service supply chain management configuration structure by applying the case study of the shooting range sport center in Northeastern, Thailand. The framework can encourage the practitioners to understand about clear processes and implement the service supply chain concept in each process. Further case studies and empirical research will be conducted about measurement and index scales to improve and assess the overall service performance.

\section{ACKNOWLEDGMENTS}

Sutinee Somabutr is a sponsored PhD student of The Royal Thai government through The Office of the Civil Service Commission (OCSC). During her PhD study at University of Plymouth, she is under the care of the Office of Educational Affairs, The Royal Thai Embassy in London, United Kingdom. Additionally, she is also sponsored by Suranaree University of Technology, Thailand.

\section{REFERENCES}

[1] Boon-itt, S., Pongpanarat, C. 2011. Measuring service supply chain management processes: The application of the Q-sort technique. Int. J. Innovation, Management and Technology. 2(3), 217-220.

[2] Boon-itt, S., Wong, C.Y., Wong, C.W.Y. 2017. Service supply chain management process capabilities: Measurement development. Int. J. Production Economics. 193, 1-11.

[3] Cho, D.W., Young, H.L., Ahn, S.H., Hwang, M.K. 2012. A framework for measuring the perforamance of service supply chain management. J. Computer Industrial Engineering. 62, 801-818.

[4] Baltacioglu, T., Ada, E., Kaplan, M.D., Yurt, O. \& Kaplan, Y. C.2007. A New Framework for Service Supply Chains. The Service Industries J. 27(2), 105-124.

[5] Vrie, J. D., Huijsman, R. 2011. Supply chain management in health service: an overview. Supply chain Management: An Int. J. 16(3), 159-165.
[6] Wu, H. \& Yang, S. (2009). Service supply chain: A conceptual framework compared with manufacturing supply chain. International Conference on Management and Service Science (MASS). IEEE, 1-4

[7] Haiyong, Y., Liu, N. 2010. Incentive mechanism in Service Supply Chain based on price contract, International Conference on E-Product E-Service and E-Entertainment (ICEEE), IEEE, 1-4

[8] Zhang, X., Song, H., Huang,G.Q. 2009. Tourism supply chain management: A new research agenda, Tourism management, 30(1), 345-358.

[9] Habib, M., Jungthirapanich, C. 2009. Research Framework of Educational Supply Chain Management for the Universities, Management and Service Science (MASS), IEEE, 1-4.

[10] Song, D., Xu, Y. 2011. Integrated Design of Service Supply Chain in the perspective of producer service outsourcing, International Conference on Management and Service Science (MASS), IEEE, 1-4.

[11] Giannakis, M. 2011. Management of service supply chains with a service-oriented reference model: the case of management consulting. Supply Chain Management: An Int. $J, 16(5), 346-361$.

[12] Sakhuja, S. and Jain, V. 2012. Service supply chain: an integrated conceptual framework. In Proceeding of 42nd International Conference on Computers and Industrial Engineering (CIE42),(Cape Town, South Africa, 16-18 July 2012).

[13] Ellram, L.M., Tate, W.L., Billington, C. 2004. Understanding and managing the services supply chain. J. Supply Chain Management: A Global Review of Purchasing and Supply. 40(4), 17-32.

[14] Li, C., Liu,Y., Cheng, J. 2008. The research on Service Supply Chain, Service Operations and Logistics, and Informatics (SOLI), IEEE, 2263-2268

[15] He, T., Ho, W., Xu,X.F. 2010. A Value-oriented Model for Managing Service Supply Chains, International Conference on Industrial Engineering and Engineering Management (IEEM), IEEE, 193-197.

[16] Chopra, S., Meindl, P. 2004. Supply Chain Management: Strategy, Planning, and Operations. Prentice Hall.

[17] Sampson, S.E. 2000. Customer-supplier duality and bidirectional supply chains in service organizations, Int. J. Service Industry Management, 11(4), 348-364. 